\title{
Sexual Dysfunction and Quality of Life in Colombian Histerectomized Women
}

\author{
Monterrosa-Castro Alvaro ${ }^{1 *}$ and Monterrosa-Blanco Angelica ${ }^{2}$ \\ ${ }^{1}$ Universidad de Cartagena, Cartagena, Colombia \\ ${ }^{2}$ Universidad de La Sabana, Bogotá, Colombia
}

*Corresponding author: Alvaro Monterrosa Castro, La Matuna, Avenida Venezuela, Edificio City Bank. Oficina 6-A, Cartagena, Colombia.

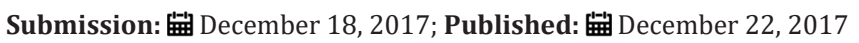

\begin{abstract}
Summary
Sexual dysfunction was identified as an associated factor to severe impairment of quality of life in hysterectomized Colombian women, using the scales Female Sexual Function Index (abbreviated version of six questions) and Menopause Rating Scale. In 390 women living in the Colombian's Caribbean, previously hysterectomized and sexually active was found that $59.7 \%$ had sexual dysfunction. It was estimated that sexual dysfunction was a not adjusted risk factor for severe deterioration of quality of life; OR: 5,35 (95\%Cl:3, 12-8,99). This study is part of the research project CAVIMEC (Calidad de vida en la menopausia y etnias colombianas).
\end{abstract}

Keywords: Menopause; Quality of life; Sexual dysfunction

\section{Introduction}

Usually is generalized the opinion that few women reveal their concerns or manifestations related with sexuality when they consult their family doctor or the gynecologist, even though they consider sex an important part of their life [1]. Sexuality as a component of climacteric women's lives must be valued through social and medical history. The availability of the Female Sexual Function Index, in its abbreviated version of six questions allows an approach from research and also from medical consultation or professional advice in health, of difficult aspects to size which make part of the sexual function. Female Sexual Function Index is a onedimensional instrument that assesses in the last four weeks: desire, arousal, lubrication, orgasm, satisfaction and pain. Each question is rated from 0 to 5 points, total score equal to or less than 19 defines sexual dysfunction [2].

The "Grupo de Investigación Salud de la Mujer" from the Universidad de of Cartagena, Colombia, through the research project CAVIMEC (Quality of life in menopause and Colombian Ethnic groups) has studied aspects related to sexuality in hysterectomized climacteric women. This analysis seeks to stablish if sexual dysfunction is an associated factor to severe impairment of quality of life.

Quality of life is a central aspect to consider when performing care to menopause and climacteric women. The World Health Organization [3] defines QoL as the individual's perception of their life, within the cultural context and value system in which they find themselves regarding their goals, expectations and concerns.

Many scales have been proposed for the study of QoL, some are generic and others specific for climacteric women. In this study was used one of the last ones, Menopause Rating Scales [4]. Sexual dysfunction and QoL are multidimensional concepts, interrelated both in reproductive and climacteric stages.

Several gynecological pathologies that cause abnormal genital bleeding, pelvic masses or cyclical pelvic pain that alter QoL, are efficiently treated with hysterectomy, one of the most frequently performed surgical interventions. However, hysterectomy and the potential surgical menopause that it produces, can cause new symptoms due to lower availability of ovarian hormones, as well as vaginal shortening and deterioration of QoL [5].

In 522 women with one or more years of being hysteroctomized, living in cities from Colombian Caribbean, a study was carried out through a form and scales: Menopause Rating Scale and Female Sexual Function Index, abbreviated version of six questions. A median age of 50 years was found, $20 \%$ had severe hot flashes and $30 \%$ had both ovaries removed in the surgery. $80 \%$ had some degree of somato/vegetative, psychological, urogenital or QoL deterioration. Half of them had severe urogenital deterioration, while $20 \%$ had severe psychological deterioration. 152(30\%) presented severe deterioration of QoL and 390 (74\%) reported sexual activity in the last four weeks.

Among the 390 sexually active women, only $21 \%$ considered 
sexual desire high/very high. Arousal level was moderate in 37\%, while $78 \%$ had genital lubrication less than half of the time, almost never or never. Less than $12 \%$ reported having orgasm almost always and $43 \%$ reported few times or never. $21 \%$ declared themselves very satisfied with their sexual life, while $33 \%$ considered themselves unsatisfied. $20 \%$ had coital pain more than half of the times, $5 \%$ never and $40 \%$ almost always or always. Table $\mathrm{N}^{\circ} 1$. The prevalence of sexual dysfunction was estimated at $59.7 \%$ and unadjusted association of sexual dysfunction with severe deterioration of quality of life, OR: 5.35 (95\% CI: 3.13-8.99).

Table $\mathbf{N}^{\circ}$ 1: Female Sexual Function Index $\left({ }^{*}\right)$ N=390 n (\%) [95\%CI].

\begin{tabular}{|c|c|c|c|c|c|}
\hline \multirow{2}{*}{ Desire } & Very High & High & Moderate & Low & Very Low or None at all \\
\hline & $30(7,6)[5,3-10,9]$ & $51(13,0)[9,9-16,9]$ & $150(38,4)[33,6-43,5]$ & $119(30,5)[26,0-35,3]$ & $40(10,2)[7,5-13,8]$ \\
\hline \multirow{2}{*}{ Arousal } & Very high & High & Moderate & Low & Very low or none at all \\
\hline & $35(8,9)[6,4-12,3]$ & $55(14,1)[10,8-18,0]$ & $146(37,4)[32,6-42,4]$ & $112(28,7)[24,3-33,5]$ & $42(10,7)[7,9-14,3]$ \\
\hline \multirow{2}{*}{ Lubrication } & $\begin{array}{l}\text { Almost always or } \\
\text { always }\end{array}$ & $\begin{array}{l}\text { Most times (more } \\
\text { than half the time) }\end{array}$ & $\begin{array}{c}\text { Sometimes (about half } \\
\text { the time) }\end{array}$ & $\begin{array}{l}\text { A few times (less than } \\
\text { half the time) }\end{array}$ & Almost never or never \\
\hline & $25(6,4)[4,2-9,4]$ & $61(15,6)[12,2-19,7]$ & $154(39,4)[34,6-44,5]$ & $95(24,3)[20,2-28,9]$ & $55(14,1)[10,8-18,0]$ \\
\hline \multirow{2}{*}{ Orgasm } & $\begin{array}{l}\text { Almost always or } \\
\text { always }\end{array}$ & $\begin{array}{l}\text { Most times (more } \\
\text { than half the time) }\end{array}$ & $\begin{array}{c}\text { Sometimes (about half } \\
\text { the time) }\end{array}$ & $\begin{array}{c}\text { A few times (less than } \\
\text { half the time) }\end{array}$ & Almost never or never \\
\hline & $45(11,5)[8,6-15,2]$ & $93(23,8)[19,7-28,4]$ & $84(21,5)[17,6-26,0]$ & $101(25,9)[21,6-30,6]$ & $67(17,1)[13,6-21,3]$ \\
\hline \multirow{2}{*}{ Satisfaction } & Very satisfied & Moderately satisfied & $\begin{array}{l}\text { About equally satisfied } \\
\text { and dissatisfied }\end{array}$ & Moderately dissatisfied & Very dissatisfied \\
\hline & $83(21,2)[17,3-25,7]$ & $101(25,9)[21,6-30,6]$ & $74(18,9)[15,2-23,3]$ & $84(21,5)[17,6-26,0]$ & $48(12,3)[9,3-16,0]$ \\
\hline \multirow{2}{*}{ Pain } & $\begin{array}{l}\text { Almost always or } \\
\text { always }\end{array}$ & $\begin{array}{l}\text { Most times (more } \\
\text { than half the time) }\end{array}$ & $\begin{array}{c}\text { Sometimes (about half } \\
\text { the time) }\end{array}$ & $\begin{array}{l}\text { A few times (less than } \\
\text { half the time) }\end{array}$ & Almost never or never \\
\hline & $147(37,6)[32,9-42,7]$ & $75(19,2)[15,5-23,5]$ & $91(23,3)[19,2-27,9]$ & $58(14,8)[11,5-18,8]$ & $19(4,8)[3,0-7,6]$ \\
\hline
\end{tabular}

Figures observed regarding the indicators of sexual function that were explored with FSFI indicate the need for health intervention, although these results should not be extrapolated openly to other communities of women, they show the scenario that many climacteric women may be experiencing after been histeromized. In another CAVIMEC report [6] we have indicated that $25.7 \%$ of Colombian hysterectomized women report severe/ very severe sexual problems.

Hysterectomy, especially when accompanied by oophorectomy, can trigger sudden onset of hot flashes, mood changes and vaginal atrophy, which are related to poor QoL and sexual deterioration [7], being directly involved hypoestrogenism and hypoandrogenism. Deciding to remove or preserve the ovaries must be meditated, oophorectomized women have worst sexual function than nonoophorectomized women, both in sexual desire, frequency and orgasmic response. The WISHeS study [8] reported that women under fifty with surgically induced menopause had greater hypoactive sexual desire disorders than others with preserved ovaries.

In another CAVIMEC report (unpublished data) we found that low sexual desire and sexual dissatisfaction are risk factors for QoL deterioration, while the presence of good sexual lubrication is a protective factor for QoL in hysterectomized women, which aims to support that an adequate vaginal health is important for satisfactory sexual function. It has been noted that half of women with genitourinary atrophy report that the symptoms interfere with sexual enjoyment.
The CAVIMEC project is a cross-sectional study conducted on women in their communities, with anonymous, voluntary participation and signing of informed consent, endorsed by the ethics committee of the Universidad de Cartagena, Colombia. It is framed in standards for health research, resolution 8430 -1993, Ministerio de Salud, República de Colombia. The results here briefly exposed and other approaches derived from hysterectomized women of the CAVIMEC project will be presented at the 16th World Congress on Menopause and at the Gynecological Endocrinology of the $18^{\text {th }}$ World Congress, in 2018.

\section{Conclusion}

In climacteric women of the Colombian Caribbean, sexually active and previously hysterectomized, it was observed that sexual dysfunction is a significant risk factor not adjusted for severe deterioration of the QoL.

\section{Financing}

Strengthening plan for research groups categorized by Colciencias. Internal Call-2017 of the Universidad de Cartagena. Colombia.

\section{References}

1. Simon JA, Kokot-Kierepa M, Goldstein J, Nappi RE (2013) Vaginal health in the United States: results from the vaginal health: insights, views \& attitudes survey. Menopause 20(10): 1043-1048.

2. Isidori A, Pozza C, Esposito K, Giugliano D, Morano S, et al. (2010) Development and Validation of a 6-Item Version of the Female Sexual 
Function Index (FSFI) as a Diagnostic Tool for Female Sexual Dysfunction. J Sex Med 7(3): 1139-1146.

3. Whoquol group (1993) Study protocol for the World Health Organisation project to develop a Quality of Life assessment instrument (Whoquol). Qual Life Res 2(2): 153-159.

4. Heinemann K, Ruebig A, Potthoff P, Schneider HP, Strelow F, et al. (2004) The Menopause Rating Scale (MRS) scale: a methodological review. Health Qual Life Outcomes 2: 45-52.

5. Kuppermann M, Learman LA, Schembri M, Gregorich SE, Jackson RA, et al. (2013) Contributions of hysterectomy and uterus-preserving surgery to health-related quality of life. Obstet Gynecol 122(1): 15-25.
6. Saavedra-Orozco H, Monterrosa-Castro A, Caraballo-Olave E, UlloqueCaamaño L, Rincón-Niño E (2014) Prevalence of sexual dysfunction, insomnia and deterioration of the quality of life in hysterectomyzed women. Rev Cienc biomed 5(2): 235-246.

7. Finch A, Metcalfe KA, Chiang JK, Elit L, McLaughlin J, et al. (2011) The impact of prophylactic salpingo-oophorectomy on menopausal symptoms and sexual function in women who carry a BRCA mutation. Gynecol Oncol. 121(1): 163-168.

8. Leiblum SR, Koochaki PE, Rodenberg CA, Barton IP, Rosen RC (2006) Hypoactive sexual desire disorder in postmenopausal women: US results from the Women's International Study of Health and Sexuality (WISHeS). Menopause 13(1): 46-56. 